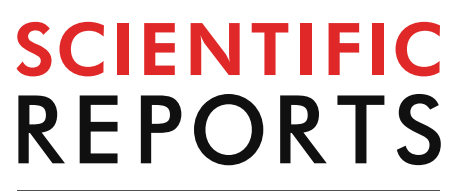

natureresearch

Check for updates

\title{
Parental psychological distress in the postnatal period in Japan: a population-based analysis of a national cross-sectional survey
}

\begin{abstract}
Kenji Takehara ${ }^{1 \bowtie}$, Maiko Suto ${ }^{1} \&$ Tsuguhiko Kato $^{2}$
Mental health assessments of both members of a couple are important when considering the childrearing environment. The prevalence and factors associated with both parents' psychological distress have not been fully investigated. A nationally representative sample from the 2016 Comprehensive Survey of Living Conditions in Japan was used to examine the prevalence of moderate and severe psychological distress in parents in the first year after childbirth. In total, 3,514 two-parent households raising children under one year old met the study criteria. The Japanese version of Kessler 6 was used to assess moderate and severe psychological distress. The prevalence of either or both parents experiencing psychological distress in the first year after birth were $15.1 \%$ and $3.4 \%$, respectively. A multivariate logistic regression analysis showed factors of fathers who worked $\geq 55 \mathrm{~h}$ a week, reduced duration of sleep in mothers, age in months of the youngest child, and high household expenditures were significantly associated with both parents simultaneously having moderate or severe psychological distress. This study implied the importance of prevention and early detection of parental psychological distress in both parents. Assessing parents' psychological distress and workstyle reform in the childcare period is an urgent issue to improve their mental health conditions.
\end{abstract}

Psychological distress in the postpartum period often manifests as depressive episodes in both men and women and is a serious health issue for parents ${ }^{1}$. Previous research has demonstrated the negative impact of maternal depression on infant hospitalization and mortality ${ }^{2}$, duration of breastfeeding ${ }^{3}$, parenting ${ }^{4}$, and child development ${ }^{5,6}$. Compared with maternal depression, paternal depression has not been recognized as a serious health issue within the general population worldwide. However, the negative effects of paternal depression on maternal and child health have been indicated by previous studies. These include an increase in inappropriate parenting behaviour ${ }^{7}$, impaired bonding with infants ${ }^{8}$, less enriching parenting activities ${ }^{9}$, adverse effects on emotional, behavioural, and psychosocial development in child ${ }^{10,11}$, and depression in adolescence ${ }^{12}$. It is also known that paternal depression has the potential to increase father's risk of suicide ${ }^{13}$ and healthcare $\operatorname{costs}^{14}$. According to a recent meta-analysis and systematic review, the estimate for paternal depression in the first year after childbirth is $8.4 \%$ [95\% Confidence Interval (CI), 7.2-9.6\% $]^{15}$. The estimate for maternal depression is slightly higher $[11.9 \% \text {, }(95 \% \text { CI: } 11.4 \%-12.5 \%)]^{16}$. The prevalence rates for any anxiety disorder among fathers in the postnatal period ranged from $2.4-18.0 \%{ }^{17}$. The prevalence of depressive episodes in fathers in the first year after birth was relatively high, compared with later years ${ }^{18}$.

Previous studies have shown that paternal depression and maternal depression are positively correlated ${ }^{15,19-22}$, and the occurrence of depression in one parent led to an increased risk of the depression in the other ${ }^{23,24}$. In addition, the prevalence of both parents being simultaneously depressed at nine months postpartum was $2.9 \%$, and research has shown that parental behaviour and breastfeeding practice deteriorate when both parents are depressed at the same time $e^{9}$. Thus, it is critical to prevent parents from becoming psychologically distressed at the same time to prevent a poor quality of child-rearing practices as well as the possibility of adverse effects such as the children's subsequent developmental delay ${ }^{10,11}$. However, the evidence is lacking regarding the prevalence

\footnotetext{
${ }^{1}$ Department of Health Policy, National Center for Child Health and Development, 10-1, Okura 2 chome, Setagaya, Tokyo 157-8535, Japan. '2Department of Social Medicine, National Center for Child Health and Development, 10-1, Okura 2 chome, Setagaya, Tokyo 157-8535, Japan. ${ }^{\circledR}$ email: takehara-k@ncchd.go.jp
} 


\begin{tabular}{|c|c|c|c|c|c|c|c|}
\hline & & \multicolumn{2}{|c|}{ Household } & \multicolumn{2}{|c|}{ Father } & \multicolumn{2}{|c|}{ Mother } \\
\hline & & n & $\%$ & $\mathbf{n}$ & $\%$ & n & $\%$ \\
\hline \multicolumn{8}{|l|}{ Household and child characteristics } \\
\hline \multirow{3}{*}{ Residential area } & Metropolitan & 793 & 22.6 & & & & \\
\hline & $\begin{array}{l}\text { City with a popula- } \\
\text { tion of over } 50,000\end{array}$ & 1,999 & 56.9 & & & & \\
\hline & $\begin{array}{l}\text { City with a popula- } \\
\text { tion of less than } \\
50,000\end{array}$ & 722 & 20.5 & & & & \\
\hline \multirow{2}{*}{ Number of children } & 1 & 1,593 & 45.3 & & & & \\
\hline & $\geq 2$ & 1921 & 54.7 & & & & \\
\hline Twin & Yes & 35 & 1.0 & & & & \\
\hline \multirow{4}{*}{ Age in months of youngest children } & $0-3$ months & 734 & 20.9 & & & & \\
\hline & 3-6 months & 872 & 24.8 & & & & \\
\hline & 6-9 months & 937 & 26.7 & & & & \\
\hline & 9-12 months & 971 & 27.6 & & & & \\
\hline \multicolumn{2}{|c|}{ Monthly household expenditure per person ${ }^{\mathrm{a}}$ (median, IQR) } & 5.7 & $4.0-7.5$ & & & & \\
\hline Sex of youngest children & Male & 1,765 & 50.2 & & & & \\
\hline \multirow{2}{*}{ Living with grand parents } & $\begin{array}{l}\text { With father's } \\
\text { parent(s) }\end{array}$ & 450 & 12.8 & & & & \\
\hline & $\begin{array}{l}\text { With mother's } \\
\text { parent(s) }\end{array}$ & 111 & 3.2 & & & & \\
\hline \multirow[b]{2}{*}{ Primary caregiver of children during daytime } & Parents only & 2,257 & 67.4 & & & & \\
\hline & $\begin{array}{l}\text { Parents and any of } \\
\text { other family mem- } \\
\text { bers and nursery }\end{array}$ & 1,092 & 32.6 & & & & \\
\hline \multicolumn{8}{|l|}{ Parental characteristics } \\
\hline Age (mean, SD) & & & & 33.9 & 6.0 & 32.1 & 5.1 \\
\hline \multirow{2}{*}{ Education $^{\mathrm{b}}$} & Low & & & 1,859 & 58.5 & 2,212 & 69.9 \\
\hline & High & & & 1,320 & 41.5 & 952 & 30.1 \\
\hline Visits hospital regularly & Yes & & & 571 & 16.3 & 584 & 16.7 \\
\hline Visits hospital due to mental health problem & Yes & & & 24 & 0.7 & 28 & 0.8 \\
\hline \multirow{2}{*}{ Number of hours sleeping per day } & $<6 \mathrm{~h}$ & & & 1,426 & 40.6 & 1,803 & 51.4 \\
\hline & $\geq 6 \mathrm{~h}$ & & & 2,084 & 59.4 & 1,704 & 48.6 \\
\hline Smoking (everyday or occasional) & Yes & & & 1,407 & 40.4 & 188 & 5.4 \\
\hline Alcohol use ( $\geq$ once per week) & Yes & & & 1749 & 50.2 & 207 & 5.9 \\
\hline Employment status & $\begin{array}{l}\text { Yes (Undertaking } \\
\text { childcare leave) }\end{array}$ & & & 3,479 & 99.3 & 1,545 & 44.0 \\
\hline \multirow{2}{*}{ Number of work hours per week } & $<55 \mathrm{~h}$ & & & 2,431 & 73.6 & & \\
\hline & $\geq 55 \mathrm{~h}$ & & & 872 & 26.4 & & \\
\hline \multirow{2}{*}{ Number of work hours per week } & No work hours & & & & & 2,675 & 80.4 \\
\hline & $\geq 1 \mathrm{~h}$ & & & & & 653 & 19.6 \\
\hline
\end{tabular}

Table 1. Basic characteristics of households, parents, and children $(n=3,514) .{ }^{a}$ Monthly household expenditure per person in May, 2016 (10,000 JPY). ${ }^{b}$ Defined graduation from 2-year college, vocational school, or less as low and 4-year college or graduate school as high.

and factors associated with individual psychological distress and simultaneous psychological distress in both partners in the postpartum period.

Therefore, the purpose of this study was to describe the prevalence of paternal and maternal psychological distress at both the individual and simultaneous psychological distress in both partners and to explore the factors associated with both parents experiencing simultaneous psychological distress using a nationwide crosssectional survey in Japan.

\section{Results}

Descriptive information for the participants is presented in Table 1 . The mean ages of fathers and mothers were 33.9 years $(S D=6.0)$ and 32.1 years $(S D=5.1)$, respectively. The number of boys was $1,765(50.2 \%)$ and the number of girls was $1,749(49.8 \%)$. The numbers of households with one child and those with two or more children were $1,593(45.3 \%)$, and 1,921 (54.7\%), respectively. Households in which parents were the main caregivers of children during daytime were 2,257 (67.4\%). Of the fathers, 3,479 (99.3\%) were employed and $872(26.4 \%)$ fathers reported working more than $55 \mathrm{~h}$ per week. Among the mothers, those who were employed, and those who worked one hour or more per week were 1,545 (44.0\%), and 653 (19.6\%), respectively. 


\begin{tabular}{|c|c|c|c|c|c|}
\hline & \multicolumn{4}{|c|}{ Age in months of their youngest children } & \multirow[b]{2}{*}{ Overall period (0-12 months) } \\
\hline & 0-3 months & 3-6 months & 6-9 months & 9-12 months & \\
\hline \multicolumn{6}{|l|}{ Fathers } \\
\hline MPD or SPD & $10.4 \%$ & $11.0 \%$ & $11.1 \%$ & $11.2 \%$ & $11.0 \%$ \\
\hline SPD & $3.3 \%$ & $3.7 \%$ & $4.5 \%$ & $3.3 \%$ & $3.7 \%$ \\
\hline \multicolumn{6}{|l|}{ Mothers } \\
\hline MPD or SPD & $11.2 \%$ & $8.7 \%$ & $11.7 \%$ & $11.5 \%$ & $10.8 \%$ \\
\hline SPD & $3.0 \%$ & $2.9 \%$ & $4.5 \%$ & $3.4 \%$ & $3.5 \%$ \\
\hline \multicolumn{6}{|c|}{ Either a couple } \\
\hline MPD or SPD & $14.7 \%$ & $16.1 \%$ & $13.9 \%$ & $15.6 \%$ & $15.1 \%$ \\
\hline SPD & $4.0 \%$ & $5.8 \%$ & $6.3 \%$ & $4.5 \%$ & $5.2 \%$ \\
\hline \multicolumn{6}{|l|}{ Both of couple } \\
\hline MPD or SPD & $3.4 \%$ & $1.8 \%$ & $4.5 \%$ & $3.6 \%$ & $3.4 \%$ \\
\hline SPD & $0.7 \%$ & $0.1 \%$ & $0.3 \%$ & $0.5 \%$ & $0.4 \%$ \\
\hline
\end{tabular}

Table 2. Prevalence of moderate and severe psychological distress among parents by age in months in the first year after birth $(\mathrm{n}=3,514)$. MPD (moderate psychological distress): the prevalence of the K6 score between 9 and 12 points. SPD (severe psychological distress): the prevalence of the K6 score $\geq 13$ points. MPD or SPD: the prevalence of the K6 score $\geq 9$ points.

The prevalence of psychological distress at both the individual and couple level in the first year after childbirth is shown in Table 2. The Japanese version of the Kessler Psychological Distress Scale (K6) was used to assess moderate psychological distress (MPD), defined as a score of 9-12, and severe psychological distress (SPD), defined as a score $\geq 13$. The prevalence of MPD or SPD (i.e. K6 $\geq 9$ ) during the first year after delivery was $11.0 \%$ for fathers and $10.8 \%$ for mothers. The prevalence of SPD (i.e. K6 $\geq 13$ ) was $3.7 \%$ for fathers and $3.5 \%$ for mothers.

The prevalence of households in which either parent was assessed at a K6 rating of $\geq 9$ (i.e. MPD or SPD) was $15.1 \%$ and $\geq 13$ (i.e. SPD) was $5.2 \%$ in the first year after delivery. The prevalence of households in which both parents were assessed at a K6 rating $\geq 9$ was $3.4 \%$ and a K6 rating $\geq 13$ was $0.4 \%$.

The associations and crude odds ratios (COR) between paternal and maternal MPD or SPD and between paternal and maternal SPD using chi-square analyses are presented in Supplementary Tables 1 and 2. Both analyses showed significant associations between paternal and maternal psychological distress, and the crude odds ratios were 4.84 (95\% CI, 3.76-6.22) and 3.66 (95\% CI, 2.04-6.58), respectively.

The results of the univariate and multivariate analysis used to explore the associations with both parents experiencing psychological distress at the same period are shown in Table 3. In the univariate analysis, both parents assessed as having MPD or SPD at the same time was significantly associated with the age in months of the youngest child, monthly household expenditure per person, and mothers or fathers who slept less than $6 \mathrm{~h}$ per night.

In multivariate logistic regression including 2,773 (78.9\%) of the sample, both parents being assessed as having MPD or SPD at the same time was significantly associated with fathers who worked $55 \mathrm{~h}$ or more per week (adjusted odds ratio (AOR), 1.61; 95\% CI, 1.05-2.49), mothers who slept less than $6 \mathrm{~h}$ per night (AOR, 1.81; 95\% CI, 1.17-2.79), children aged 6-12 months (vs. children aged 0-6 months; AOR, 1.58; 95\% CI, 1.02-2.45), and high household expenditure per person (lower half vs. upper half: AOR, 2.09; 95\% CI, 1.33-3.28). No other variables were found to be significantly associated with both parents reporting MPD or SPD at the same time.

For a sensitivity analysis, fathers who were assessed as having MPD or SPD were significantly more likely in the multivariate analysis (Supplementary Table 3) to be have slept less than $6 \mathrm{~h}$ per night, work $55 \mathrm{~h}$ or more per week, and have a high monthly household expenditure per person. Mothers who were assessed as having MPD or SPD were significantly more likely in the multivariate analysis (Supplementary Table 4) to be mothers who had husbands who smoked, had lower alcohol consumption, had a child aged 6-12 months, and being mothers who slept less than $6 \mathrm{~h}$ per night.

\section{Discussion}

This is the first study to describe the trends in the prevalence of psychological distress in the first year after delivery and their associated factors at both at the individual level and simultaneous psychological distress in both partners. We identified factors associated with both parents having MPD or SPD at the same time during the first year postpartum using data from a nationwide population-based survey. Overall, we found that approximately $11 \%$ of fathers and mothers were at risk for either MPD or SPD in the first year after the birth of their child based on ratings on the K6. We also found that the proportion of households in which either or both parents were identified as having MPD was $15.1 \%$ or SPD was $3.4 \%$. When one parent developed MPD or SPD, the odds ratio of the partner developing MPD or SPD was 4.84 times higher and developing SPD was 3.66 times higher compared with those partners without distress.

The response rate of the Comprehensive Survey of Living Conditions in Japan (CSLC) in 2016 was $77.5 \%$. Most of the non-respondents of the CSLC were young and living in single households, especially those who were 


\begin{tabular}{|c|c|c|c|c|c|c|c|c|c|c|}
\hline & & \multicolumn{2}{|c|}{$\begin{array}{l}\text { Both } \\
\text { parents } \\
\text { scored } \\
\text { K6 } \geq 9 \\
(\mathrm{n}=118)\end{array}$} & \multicolumn{2}{|c|}{$\begin{array}{l}\text { Either or both } \\
\text { parents scored } \\
\text { K6<9 }\end{array}$} & \multirow[b]{2}{*}{$\mathbf{P}$} & \multirow{2}{*}{\multicolumn{2}{|c|}{\begin{tabular}{|l|} 
Crude OR \\
$(95 \% \mathrm{CI})$ \\
\end{tabular}}} & \multirow{2}{*}{\multicolumn{2}{|c|}{$\begin{array}{l}\text { Adjusted OR } \\
(95 \% \mathrm{CI})\end{array}$}} \\
\hline & & $\mathbf{n}$ & $\%$ & n & $\%$ & & & & & \\
\hline \multicolumn{11}{|l|}{ Household } \\
\hline \multirow{3}{*}{ Residential area } & Metropolitan & 25 & 3.2 & 768 & 96.8 & 0.889 & Ref & & - & - \\
\hline & City with a population of over 50,000 & 67 & 3.4 & 1,932 & 96.6 & & 1.07 & $(0.71-1.70)$ & - & - \\
\hline & City with a population of less than 50,000 & 26 & 3.6 & 696 & 96.4 & & 1.15 & $(0.70-2.01)$ & - & - \\
\hline \multirow{2}{*}{ Number of children } & 1 & 49 & 3.1 & 1,544 & 96.9 & 0.398 & Ref & & Ref & \\
\hline & $\geq 2$ & 69 & 3.6 & 1,852 & 96.4 & & 1.17 & $(0.83-1.70)$ & 1.30 & $(0.84-2.01)$ \\
\hline \multirow{2}{*}{ Twin $^{a}$} & No & 118 & 3.4 & 3,361 & 96.6 & 0.631 & - & - & - & - \\
\hline & Yes & 0 & 0 & 35 & 100.0 & & - & - & - & - \\
\hline \multirow{2}{*}{ Month age of youngest children } & $0-6$ months & 41 & 2.6 & 1,565 & 97.4 & 0.015 & Ref & & Ref & \\
\hline & $6-12$ months & 77 & 4.0 & 1,831 & 96.0 & & 1.61 & $(1.09-2.36)$ & 1.58 & $(1.02-2.45)$ \\
\hline \multirow{2}{*}{ Sex of youngest children } & Male & 62 & 3.5 & 1,703 & 96.5 & 0.609 & Ref & & Ref & \\
\hline & Female & 56 & 3.2 & 1,693 & 96.8 & & 0.91 & $(0.65-1.31)$ & 0.96 & $(0.64-1.45)$ \\
\hline \multirow{2}{*}{ Monthly household expenditure per person } & Lower half & 41 & 2.4 & 1,681 & 97.6 & 0.002 & Ref & & Ref & \\
\hline & Upper half & 77 & 4.3 & 1,715 & 95.7 & & 1.84 & $(1.25-2.71)$ & 2.09 & $(1.33-3.28)$ \\
\hline \multirow{2}{*}{ Main caregiver of children during daytime } & $\begin{array}{l}\text { Parents and any of other family members and } \\
\text { nursery }\end{array}$ & 47 & 4.3 & 1,045 & 95.7 & & Ref & & Ref & \\
\hline & Parents only & 69 & 3.1 & 2,188 & 96.9 & 0.064 & 0.70 & $(0.50-1.02)$ & 0.74 & $(0.46-1.20)$ \\
\hline \multicolumn{11}{|l|}{ Father } \\
\hline \multirow{2}{*}{ Age } & $<30$ & 32 & 4.0 & 774 & 96.0 & 0.272 & Ref & & Ref & \\
\hline & $\geq 30$ & 86 & 3.2 & 2,622 & 96.8 & & 0.79 & $(0.53-1.20)$ & 0.90 & $(0.57-1.40)$ \\
\hline \multirow{2}{*}{ Education } & Low & 66 & 3.6 & 1,793 & 96.4 & 0.572 & Ref & & Ref & \\
\hline & High & 42 & 3.2 & 1,278 & 96.8 & & 0.89 & $(0.62-1.32)$ & 0.90 & $(0.57-1.40)$ \\
\hline \multirow{2}{*}{ Under treatment other than mental illness } & No & 99 & 3.3 & 2,864 & 96.7 & 0.816 & Ref & & Ref & \\
\hline & Yes & 19 & 3.5 & 518 & 96.5 & & 1.06 & $(0.65-1.73)$ & 1.05 & $(0.60-1.83)$ \\
\hline \multirow{2}{*}{ Smoking } & No & 61 & 2.9 & 2,011 & 97.1 & 0.077 & Ref & & Ref & \\
\hline & Yes & 57 & 4.1 & 1,350 & 95.9 & & 1.39 & $(0.98-2.01)$ & 1.54 & $(0.99-2.39)$ \\
\hline \multirow{2}{*}{ Alcohol use ( $\geq$ once per week) } & No & 65 & 3.7 & 1,670 & 96.3 & 0.205 & Ref & & Ref & \\
\hline & Yes & 52 & 3.0 & 1,697 & 97.0 & & 0.79 & $(0.56-1.14)$ & 0.72 & $(0.47-1.10)$ \\
\hline \multirow{2}{*}{ Number of hours slept each night } & $\geq 6 \mathrm{~h}$ & 59 & 2.8 & 2,025 & 97.2 & 0.035 & Ref & & Ref & \\
\hline & $<6 \mathrm{~h}$ & 59 & 4.1 & 1,367 & 95.9 & & 1.48 & $(1.04-2.14)$ & 1.28 & $(0.84-1.95)$ \\
\hline Number of work hours ner week & $<55 \mathrm{~h}$ & 76 & 3.1 & 2,355 & 96.9 & 0.087 & Ref & & Ref & \\
\hline Number of work hours per week & $\geq 55 \mathrm{~h}$ & 38 & 4.4 & 834 & 95.6 & & 1.41 & $(0.96-2.10)$ & 1.61 & $(1.05-2.49)$ \\
\hline Mother & & & & & & & & & & \\
\hline Age & $<30$ & 36 & 3.3 & 1,059 & 96.7 & 0.876 & Ref & & - & - \\
\hline Age & $\geq 30$ & 82 & 3.4 & 2,337 & 96.6 & & 1.03 & $(0.69-1.54)$ & - & - \\
\hline Eduction & Low & 82 & 3.7 & 2,130 & 96.3 & 0.166 & Ref & & - & - \\
\hline Equecation & High & 26 & 2.7 & 926 & 97.3 & & 0.73 & $(0.48-1.14)$ & - & - \\
\hline Under treatment other than mental illnece & No & 97 & 3.3 & 2,856 & 96.7 & 0.809 & Ref & & Ref & \\
\hline Under treatment other than mental illness & Yes & 19 & 3.5 & 526 & 96.5 & & 1.06 & $(0.73-1.89)$ & 1.16 & $(0.67-2.00)$ \\
\hline Smoking & No & 113 & 3.4 & 3,187 & 96.6 & 0.573 & Ref & & Ref & \\
\hline Smoking & Yes & 5 & 2.7 & 183 & 97.3 & & 0.77 & $(0.33-1.91)$ & 0.51 & $(0.18-1.48)$ \\
\hline Alcohol use (>once ner week) & No & 109 & 3.3 & 3,176 & 96.7 & 0.426 & Ref & & Ref & \\
\hline Alconol use ( $\geq$ once per week) & Yes & 9 & 4.3 & 198 & 95.7 & & 1.32 & $(0.68-2.65)$ & 1.27 & $(0.53-3.06)$ \\
\hline Number of hours slent each night & $\geq 6 \mathrm{~h}$ & 44 & 2.6 & 1,660 & 97.4 & 0.020 & Ref & & Ref & \\
\hline Number of hours slept each night & $<6 \mathrm{~h}$ & 72 & 4.0 & 1,731 & 96.0 & & 1.57 & $(1.10-2.30)$ & 1.81 & $(1.17-2.79)$ \\
\hline Number f work hours ner week & No work hours & 82 & 3.1 & 2,593 & 96.9 & 0.117 & Ref & & Ref & \\
\hline Number of work hours per week & $\geq 1 \mathrm{~h}$ & 28 & 4.3 & 625 & 95.7 & & 1.42 & $(0.93-2.19)$ & 1.13 & $(0.64-1.95)$ \\
\hline
\end{tabular}

Table 3. Crude and adjusted odds ratio between parental psychological distress (both parents scored K6 $\geq 9$; MPD or SPD) and potential risk factors such as socio-economic status, health behavior, and working situation among Japanese parents. $(n=3,514) .2,773$ couples were included in the multivariate analysis. 
living in urban areas, when compared to the distribution of the National Census ${ }^{25}$. Thus, the representativeness of the population of this study compared to the census population is high.

In comparison with the prevalence of paternal, maternal, and both parents' depression at nine months postpartum that was reported in a previous study conducted in the United States, which were 7.4\%, 11.5\%, and 2.9\%, respectively $^{9}$, the prevalence of fathers, mothers, and both of couple having MPD or SPD between 9-12 months postpartum in this study was higher $(11.2 \%, 11.5 \%$, and $3.6 \%$, respectively). The prevalence of mothers was almost same ${ }^{9}$. The prevalence of psychological distress for fathers in this study was higher than the prevalence of paternal depression reported in a previous meta-analysis ${ }^{15}$, but the prevalence of psychological distress for mothers in this study was similar to the prevalence of maternal depression reported in a previous systematic review $^{16}$. We found that the prevalence of MPD or SPD in this period might be different according to the age in months of the youngest child because the prevalence of 0-6 months postpartum for both parents and mothers was lower than those parents whose youngest child was 6-12 months postpartum.

To the best of our knowledge, this is also the first study using a national survey to explore the factors associated with both parents experiencing psychological distress in the same period in the first year after birth. Fathers who worked $55 \mathrm{~h}$ or more per week, mothers who slept less than $6 \mathrm{~h}$ per night, the age in months of the youngest child, and high household expenditure per person, were associated with both parents having MPD or SPD at the same time. The negative effects of long work hours and working weekends on the mental health status of both parents have previously been reported ${ }^{26-28}$. Our results have shown that $26.4 \%$ of fathers worked $55 \mathrm{~h}$ or more per week in the first year after delivery and that long work hours among fathers may raise the possibility of psychological distress among fathers as well as mothers. There are a number of systematic reviews that have examined poor and interrupted sleep and its negative effects on mental health in the postnatal period ${ }^{29-31}$, and parents who are raising young children need to have time for housework, childcare, and rest at home. In particular, there are increased time demands related to childcare, such as feeding, changing diapers, and getting children to sleep during the initial years after birth. If the father works long hours, the primary responsibility for most of the housework and childcare falls upon the mother, who may not receive enough support from her partner. As a result, both parents may be exhausted by the fathers' long working hours. The promotion of worklife balance is an urgent issue for parents with young children to improve their quality of life and mental health.

Although a significant association between higher monthly household expenditure per person and both parents experiencing psychological distress in the same time period was observed, we cannot conclude a causal relationship. The relationship between mental health problems and economic burdens is an issue that has been extensively examined at the global, national, household, and individual level ${ }^{32-34}$. In addition to the increase in the healthcare cost in society, factors that contribute to mental health problems include decreases in earnings, increases in household expenditures, and the unpaid costs for informal caregivers for those with mental illnesses. In this study, we speculate that the increase in the household expenditure is not the cause of psychological distress but the result. Further longitudinal studies are necessary to show the effect of psychological distress on household expenditure.

Even when one parent experiences poor mental health, the quality of child-rearing in the home deteriorates ${ }^{3,7,9,35}$, so the adverse effect on the child's environment may be even greater if both parents are psychologically distressed. From the perspective of child development and parental quality of life, an environment in which both parents experience psychological distress may be a critical situation that should be addressed as soon as possible. Unintentionally, parental psychological distress may affect the level of care given to children, even leading to neglect. Neglect during early childhood is known to contribute to poor outcomes in later life, such as antisocial behaviour in adolescent boys and depression in adults ${ }^{36,37}$.

Limitations. The current study has several limitations that should be considered. First, the K6 in the CSLC was assessed not through a structured interview but by a self-administered questionnaire. This scale, when previously used and developed in the United States ${ }^{38}$, and then validated in Japan ${ }^{39}$, was administered using a structured interview. Second, the identification of parents and children was made using a parent/child identification variable included in the CSLC dataset. Therefore, we are not entirely certain of the biological relationship between the parents and children as parent-child relationships, foster parents, and other familial arrangements that were included in the original data collection. Third, reverse causation should be considered in this study because CSLC employed a cross-sectional design; however, the negative effects of long work hours ${ }^{26-28}$ and poor sleep ${ }^{29-31}$ on mental health have been well established in previous research. In addition, age cannot suddenly change according to an event because the age of a child increases continuously and at a regular interval. Fourth, the effects of data sparse bias in the multivariate analysis should be considered because of the large number of covariates compared to the number of outcome events. However, there were no noticeable differences of the direction or value of the odds ratios between the univariate and multivariate analyses. Finally, the effects of psychological history, including mental health status and psychiatric consultation in the prenatal period and before the pregnancy, which is well known as an important risk factor for mental health status in the postnatal period of both mothers and fathers ${ }^{40,41}$, were not adjusted for in the multivariate analysis as the variables were limited in the CSLC. Despite these limitations, this study, which used a nationwide population-based dataset and included couples, identified several important findings.

\section{Conclusion}

The prevalence for either or both parents experiencing MPD or SPD in the first year after birth was $15.1 \%$ and $3.4 \%$, respectively. The condition where both parents reported having MPD or SPD at the same time was associated with fathers worked $55 \mathrm{~h}$ or more per week, reduced hours of sleep, age in months of the youngest child, and high household expenditures. To prevent parental psychological distress, mental health assessments during 


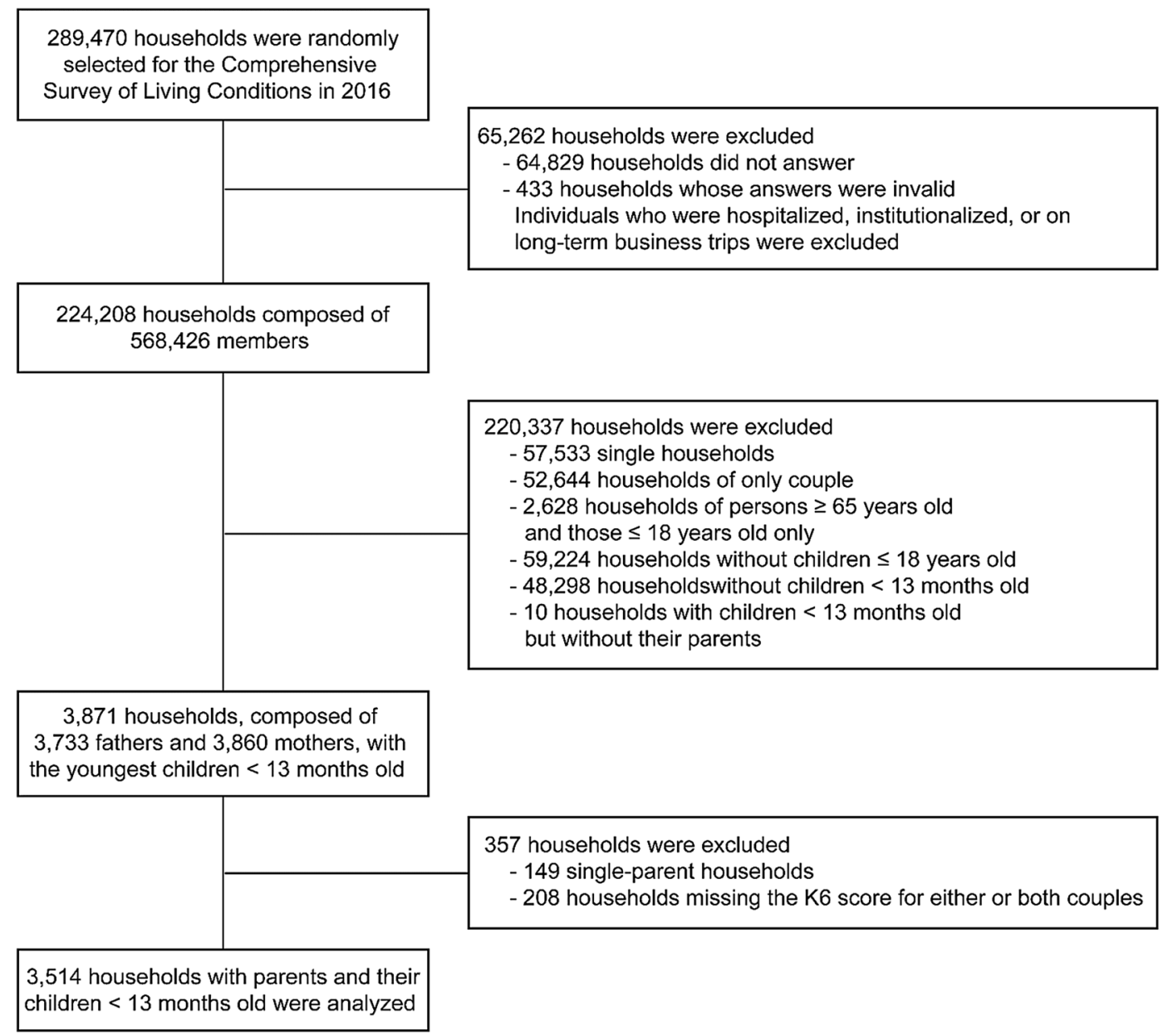

Figure 1. Flow chart of data extraction.

the postpartum period should be promoted among both mothers and fathers. Especially, the workplace may have an important role in assessment and support of psychological distress among fathers because there are few other ways to outreach them during this period. Along with enhancing the quality of health service, improving the promotion of work-life balance is another urgent issue for parents with young children to promote parental mental health.

\section{Methods}

Study population. We analysed the data from the Comprehensive Survey of Living Conditions in Japan (CSLC), which is a repeated national cross-sectional survey conducted by the Ministry of Health, Labour, and Welfare of Japan (MHLW). A summary of the CSLC is published each year ${ }^{42}$. The CSLC applied a stratified random-sampling method based on enumeration districts from the annual census. In the 2016 survey, 5,410 enumeration districts were selected randomly, and all of the members of the 289,470 households within the selected districts were recruited for participation. Individuals who were hospitalized, institutionalized, or on long-term business trips were excluded from the CSLC. Valid responses were collected from 224,208 households (response rate: $77.5 \%$ ), which comprised 568,426 members. The survey was implemented on June 2, 2016. The data is one of the government survey data with limited accessibility.

The inclusion criteria in this study were (1) being a couple who participated in the CSLC in 2016; (2) either or both parents were 65 years or younger, and (3) being a couple who had a child $<13$ months old. The exclusion criterion was having missing values on the K6 scores for either or both parents. The flow chart of data extraction is shown in Fig. 1. Out of the 224,208 households responding to the CSLC, we extracted 3,871 households with at least one child under the age of 12 months for analysis in this study. There were 38 households with two children under one year old. Of these 38 households, 34 households had twins, and the remaining four households had non-twin siblings. In the case of non-twin siblings, only data from the younger child were included. Out of the 3,871 households, 149 households which had either no father or mother, and 208 households that did not have a K6 score for either or both parents were excluded from this study. In total, 3,514 households, composed of 3,514 fathers and 3,514 mothers, met the above criteria from the original CSLC data set and were included in the final analysis. 
Measurement. The individual and household data were collected via a self-administered questionnaire as part of the CSLC. A data collector distributed and collected the questionnaires during visits to participants' homes. Psychological distress was assessed using the Japanese version of the Kessler Psychological Distress Scale (K6) in the CSLC questionnaire. The K6 consists of six questions that examine the frequency during the last 30 days of the following items: (1) nervousness, (2) hopelessness, (3) restlessness or fidgetiness, (4) being so depressed that nothing could cheer you up, (5) feeling that everything is an effort, and (6) worthlessness. The responses for each question range from 0: None of the Time to 4: All of the Time with total scores ranging from 0 to 24 points. The K6 has been validated against the classifications for anxiety and mood disorder of the American Psychiatric Association's Diagnostic and Statistical Manual of Mental Health Disorders, 4th edition, in previous studies via structured interviews ${ }^{38,39}$.

The optimal cut-off scores of the Japanese version of the K6 has been examined. The K6 score $\geq 13$ is often used to indicate severe or serious psychological distress ${ }^{43-46}$. The performance of the Japanese version of the K6 was examined using the areas under the receiver operator characteristics curves (AUCs) and stratum-specific likelihood ratios (SSLRs) ${ }^{39}$. The AUC was excellent with a high value of 0.94 (95\% CI, 0.88-0.99) and the SSLRs for a score of between $6-8$ points, $9-13$ points, $14-24$ points on K6 were 4.9 (95\% CI, 1.7-11.2), 16 (95\% CI, 6.1-34.0), and 110 (95\% CI, 11-400), respectively ${ }^{39}$. A likelihood ratio greater than 10 is considered to be an informative criterion in the diagnostic process for a disease ${ }^{47,48}$. These results showed that a K6 score $\geq 9$ is one of the optimal cut-off points, although some previous studies have adopted a K6 score $\geq 5$ as a cut-off point to define moderate psychological distress ${ }^{46,49,50}$. The same cut-off scores on the K6 are typically adopted for Japanese men and women. Therefore, in the current study, for both fathers and mothers, we used a score between 9 and 12 to indicate moderate psychological distress (MPD), and a score of greater than or equal to 13 was used to indicate severe psychological distress (SPD).

Age in months of the youngest child was calculated using their birth year and month on the date of survey implementation, which was June 2, 2016. The date of their birth was not surveyed in the CSLC. For example, in the case of children born in March 2016 and in September 2015, their age was classified as two months old and eight months old, respectively. As an exception, a child born in either May or June 2016 was classified as being less than one month of age because of proximity to the date of the CSLC. The age in month of the youngest child was divided into two periods: birth to 6 months, 0 days postpartum (0-6 months); and 6 months, 1 day to 12 months, 0 days postpartum (6-12 months). In addition, birth to 12 months, 0 days was defined as the overall study period (0 to 12 months). This period was used to consider results presented in the latest meta-analysis regarding paternal depression ${ }^{15}$.

Participants were asked to consider their monthly household expenditure per person and employment status in the past month. The number of work hours per week was provided for the period between16th May to 22nd May. The average number of hours slept per night in May, 2016 was assessed. Different categorizations of weekly work hours were used for fathers and mothers in this study. In Japan, work hours are defined in the Labor Standards Law as being $40 \mathrm{~h}$ or less per week, and overtime hours that are up to $15 \mathrm{~h}$ per week are allowed by the specific labor-management agreement pursuant to Article 36 of the Labor Standard Act. Therefore, working 55 or more hours in a week was defined as working inappropriately long work hours for fathers in this study. In contrast, most women utilize childcare leave in the first year after delivery. Thus, weekly work hours for mothers were dichotomized based on whether they worked one hour or more per week.

Data analysis. We measured the means and frequencies of the socioeconomic status, health behaviours, and working environments in the household for both fathers and mothers. The proportions of households in which either one or both parents were assessed as having MPD and SPD were also reported. The crude odds ratio (COR) with $95 \%$ CI for the association between paternal and maternal psychological distress (K6 $\geq 9$ and $\mathrm{K} 6 \geq 13$ ) was calculated using univariate logistic regression.

The crude odds ratios with $95 \%$ CI for the association between both parents scoring K6 $\geq 9$ and K6 $\geq 13$ were calculated using a univariate analysis. The parity, monthly household expenditure, main caregiver of children during daytime, children's characteristics such as age in months and sex, paternal characteristics such as age, education, health condition, smoking, drinking, number of hours slept, and number of work hours, and maternal characteristics such as health condition, smoking, drinking, number of hours slept, and number of work hours, were analysed using univariate and multivariate logistic regression with complete-case analysis in each analysis. Parental, paternal, and maternal psychological distress were set as the dependent variables. In the multivariate analysis, 2,773 couples were included without any missing variables. As a sensitivity analysis, the COR and AOR with $95 \%$ CI was calculated to examine the association between these factors, paternal, and maternal psychological distress factors separately.

The alpha level was set at $5 \%$. No imputations were completed for missing data in this study. All statistical analyses were performed with IBM SPSS statistics version 19.0 (IBM, Armonk, NY).

Ethical considerations. The use of de-identified individual-level data from the CSLC for scientific research was approved by the MHLW through the official application procedure under Article 33 of the Statistics Act (March 1, 2018). The informed consent was waived in the CSLC because this fundamental statistical survey was conducted to be based on the Statistics Act. We also did not obtain the consent in this study because we performed only secondary data analysis using the national statistics. This study was approved by the Japanese National Center for Child Health and Development ethics committee (No. 1533). This study was conducted to be based on the Ethical Guidelines for Medical and Health Research Involving Human Subjects in Japan. 
Received: 3 March 2020; Accepted: 3 August 2020

Published online: 13 August 2020

\section{References}

1. Munk-Olsen, T., Laursen, T. M., Pedersen, C. B., Mors, O. \& Mortensen, P. B. New parents and mental disorders: A populationbased register study. JAMA J. Am. Med. Assoc. 296, 2582-2589. https://doi.org/10.1001/jama.296.21.2582 (2006).

2. Jacques, N. Prenatal and postnatal maternal depression and infant hospitalization and mortality in the first year of life: A systematic review and meta-analysis. J. Affect. Disord. 243, 201-208. https://doi.org/10.1016/j.jad.2018.09.055 (2018).

3. Dias, C. C. \& Figueiredo, B. Breastfeeding and depression: A systematic review of the literature. J. Affect. Disord. 171, 142-154. https://doi.org/10.1016/j.jad.2014.09.022 (2015).

4. Field, T. Postpartum depression effects on early interactions, parenting, and safety practices: A review. Infant Behav. Dev. 33, 1-6. https://doi.org/10.1016/j.infbeh.2009.10.005 (2010).

5. Hoffman, C., Dunn, D. M. \& Njoroge, W. F. M. Impact of postpartum mental illness upon infant development. Curr Psychiatry Rep. 19, 100. https://doi.org/10.1007/s11920-017-0857-8 (2017).

6. Kingston, D., Tough, S. \& Whitfield, H. Prenatal and postpartum maternal psychological distress and infant development: A systematic review. Child Psychiatry Hum. Dev. 43, 683-714. https://doi.org/10.1007/s10578-012-0291-4 (2012).

7. Takehara, K., Suto, M., Kakee, N., Tachibana, Y. \& Mori, R. Prenatal and early postnatal depression and child maltreatment among Japanese fathers. Child Abuse Negl. 70, 231-239. https://doi.org/10.1016/j.chiabu.2017.06.011 (2017).

8. Kerstis, B. et al. Association between parental depressive symptoms and impaired bonding with the infant. Arch. Womens Ment. Health 19, 87-94. https://doi.org/10.1007/s00737-015-0522-3 (2016).

9. Paulson, J. F., Dauber, S. \& Leiferman, J. A. Individual and combined effects of postpartum depression in mothers and fathers on parenting behavior. Pediatrics 118, 659-668. https://doi.org/10.1542/peds.2005-2948 (2006).

10. Ramchandani, P., Stein, A., Evans, J. \& O’Connor, T. G. Paternal depression in the postnatal period and child development: A prospective population study. Lancet 365, 2201-2205. https://doi.org/10.1016/s0140-6736(05)66778-5 (2005).

11. Wilson, S. \& Durbin, C. E. Effects of paternal depression on fathers' parenting behaviors: A meta-analytic review. Clin. Psychol. Rev. 30, 167-180. https://doi.org/10.1016/j.cpr.2009.10.007 (2010).

12. Lewis, G., Neary, M., Polek, E., Flouri, E. \& Lewis, G. The association between paternal and adolescent depressive symptoms: Evidence from two population-based cohorts. Lancet Psychiatry 4, 920-926. https://doi.org/10.1016/s2215-0366(17)30408-x (2017).

13. Quevedo, L. et al. Risk of suicide and mixed episode in men in the postpartum period. J. Affect. Disord. 132, 243-246. https://doi. org/10.1016/j.jad.2011.01.004 (2011)

14. Edoka, I. P., Petrou, S. \& Ramchandani, P. G. Healthcare costs of paternal depression in the postnatal period. J. Affect. Disord. 133, 356-360. https://doi.org/10.1016/j.jad.2011.04.005 (2011).

15. Cameron, E. E., Sedov, I. D. \& Tomfohr-Madsen, L. M. Prevalence of paternal depression in pregnancy and the postpartum: An updated meta-analysis. J. Affect. Disord. 206, 189-203. https://doi.org/10.1016/j.jad.2016.07.044 (2016).

16. Woody, C. A., Ferrari, A. J., Siskind, D. J., Whiteford, H. A. \& Harris, M. G. A systematic review and meta-regression of the prevalence and incidence of perinatal depression. J. Affect. Disord. 219, 86-92. https://doi.org/10.1016/j.jad.2017.05.003 (2017).

17. Leach, L. S., Poyser, C., Cooklin, A. R. \& Giallo, R. Prevalence and course of anxiety disorders (and symptom levels) in men across the perinatal period: A systematic review. J. Affect. Disord. 190, 675-686. https://doi.org/10.1016/j.jad.2015.09.063 (2016).

18. Dave, S., Petersen, I., Sherr, L. \& Nazareth, I. Incidence of maternal and paternal depression in primary care: A cohort study using a primary care database. Arch. Pediatr. Adolesc. Med. 164, 1038-1044. https://doi.org/10.1001/archpediatrics.2010.184 (2010).

19. Nishimura, A., Fujita, Y., Katsuta, M., Ishihara, A. \& Ohashi, K. Paternal postnatal depression in Japan: an investigation of correlated factors including relationship with a partner. BMC Pregnancy Childbirth 15, 128. https://doi.org/10.1186/s12884-015-0552-x (2015).

20. Paulson, J. F. \& Bazemore, S. D. Prenatal and postpartum depression in fathers and its association with maternal depression: A meta-analysis. JAMA J. Am. Med. Assoc. 303, 1961-1969. https://doi.org/10.1001/jama.2010.605 (2010).

21. Anding, J. E., Rohrle, B., Grieshop, M., Schucking, B. \& Christiansen, H. Couple comorbidity and correlates of postnatal depressive symptoms in mothers and fathers in the first two weeks following delivery. J. Affect. Disord. 190, 300-309. https://doi.org/10.1016/j. jad.2015.10.033 (2016).

22. Nishigori, H. et al. The prevalence and risk factors for postpartum depression symptoms of fathers at one and 6 months postpartum: an adjunct study of the Japan Environment \& Children's Study. J. Matern.-Fetal Neonatal Med. 1-8. https://doi.org/10.1080/14767 058.2018.1560415 (2019).

23. Wee, K. Y., Skouteris, H., Pier, C., Richardson, B. \& Milgrom, J. Correlates of ante- and postnatal depression in fathers: A systematic review. J. Affect. Disord. 130, 358-377. https://doi.org/10.1016/j.jad.2010.06.019 (2011).

24. Paulson, J. F., Bazemore, S. D., Goodman, J. H. \& Leiferman, J. A. The course and interrelationship of maternal and paternal perinatal depression. Arch. Womens Ment. Health 19, 655-663. https://doi.org/10.1007/s00737-016-0598-4 (2016).

25. Ministry of Internal Affairs and Communications. Report of Advisory No. 118 About Change of National Life Basics Investigation, https://www.soumu.go.jp/main_content/000590416.pdf. Accessed 2 Sep 2019 (2018).

26. Weston, G., Zilanawala, A., Webb, E., Carvalho, L. A. \& McMunn, A. Long work hours, weekend working and depressive symptoms in men and women: findings from a UK population-based study. J. Epidemiol. Commun. Health 73, 465-474. https://doi. org/10.1136/jech-2018-211309 (2019).

27. Hino, A., Inoue, A., Mafune, K. \& Hiro, H. The effect of changes in overtime work hours on depressive symptoms among Japanese white-collar workers: A 2-year follow-up study. J. Occup. Health https://doi.org/10.1002/1348-9585.12054 (2019).

28. Theorell, T. et al. A systematic review including meta-analysis of work environment and depressive symptoms. BMC Public Health 15, 738. https://doi.org/10.1186/s12889-015-1954-4 (2015).

29. Lawson, A., Murphy, K. E., Sloan, E., Uleryk, E. \& Dalfen, A. The relationship between sleep and postpartum mental disorders: A systematic review. J. Affect. Disord. 176, 65-77. https://doi.org/10.1016/j.jad.2015.01.017 (2015).

30. Bhati, S. \& Richards, K. A systematic review of the relationship between postpartum sleep disturbance and postpartum depression. J. Obstet. Gynecol. Neonatal Nurs. JOGNN 44, 350-357. https://doi.org/10.1111/1552-6909.12562 (2015).

31. Zhai, L., Zhang, H. \& Zhang, D. Sleep duration and depression among adults: A meta-analysis of prospective studies. Depress. Anxiety 32, 664-670. https://doi.org/10.1002/da.22386 (2015).

32. World Health Organization. Investing in Mental Health: Evidence for Action. 2013. https://apps.who.int/iris/handle/10665/87232. Accessed 2 Sep 2019 (2013).

33. Doran, C. M. \& Kinchin, I. A review of the economic impact of mental illness. Aust. Health Rev. 43, 43-48. https://doi.org/10.1071/ ah16115 (2019).

34. Lancet, T. The high cost of unpaid mental health care. Lancet 389, 1274. https://doi.org/10.1016/s0140-6736(17)30871-1 (2017).

35. Davis, R. N., Davis, M. M., Freed, G. L. \& Clark, S. J. Fathers' depression related to positive and negative parenting behaviors with 1-year-old children. Pediatrics 127, 612-618. https://doi.org/10.1542/peds.2010-1779 (2011).

36. Infurna, M. R. et al. Associations between depression and specific childhood experiences of abuse and neglect: A meta-analysis. J. Affect. Disord. 190, 47-55. https://doi.org/10.1016/j.jad.2015.09.006 (2016). 
37. McGuigan, W. M., Luchette, J. A. \& Atterholt, R. Physical neglect in childhood as a predictor of violent behavior in adolescent males. Child Abuse Negl. 79, 395-400. https://doi.org/10.1016/j.chiabu.2018.03.008 (2018).

38. Kessler, R. C. et al. Screening for serious mental illness in the general population. Arch. Gen. Psychiatry 60, 184-189 (2003).

39. Furukawa, T. A. et al. The performance of the Japanese version of the K6 and K10 in the World Mental Health Survey Japan. Int. J. Methods Psychiatric Res. 17, 152-158. https://doi.org/10.1002/mpr.257 (2008).

40. Edward, K. L., Castle, D., Mills, C., Davis, L. \& Casey, J. An integrative review of paternal depression. Am. J. Men's Health 9, 26-34. https://doi.org/10.1177/1557988314526614 (2015).

41. O'hara, M. W. \& Swain, A. M. Rates and risk of postpartum depression-a meta-analysis. Int. Rev. Psychiatry 8, 37-54 (1996).

42. The Ministry of Health Labour and Welfare. Comprehensive Survey of Living Conditions 2016. https://www.mhlw.go.jp/english/ database/db-hss/dl/report_gaikyo_2016.pdf. Accessed 2 Oct 2018 (2017).

43. Eguchi, H. \& Wada, K. Mental health of working-age populations in Japan who provide nursing care for a person at home: A cross-sectional analysis. J. Occup. Health 60, 458-466. https://doi.org/10.1539/joh.2017-0295-OA (2018).

44. Tanji, F., Tomata, Y., Zhang, S., Otsuka, T. \& Tsuji, I. Psychological distress and completed suicide in Japan: A comparison of the impact of moderate and severe psychological distress. Prev. Med. 116, 99-103. https://doi.org/10.1016/j.ypmed.2018.09.007 (2018).

45. Fujiwara, M. et al. Smoking among adults with serious psychological distress: Analysis of anonymized data from a national crosssectional survey in Japan. J. Affect. Disord. 239, 131-137. https://doi.org/10.1016/j.jad.2018.07.008 (2018).

46. Nishi, D., Susukida, R., Usuda, K., Mojtabai, R. \& Yamanouchi, Y. Trends in the prevalence of psychological distress and the use of mental health services from 2007 to 2016 in Japan. J. Affect. Disord. 239, 208-213. https://doi.org/10.1016/j.jad.2018.07.016 (2018).

47. Jaeschke, R., Guyatt, G. H. \& Sackett, D. L. Users' guides to the medical literature. III. How to use an article about a diagnostic test. B. What are the results and will they help me in caring for my patients? The Evidence-Based Medicine Working Group. JAMA 271, 703-707 (1994).

48. Schmitz, N., Kruse, J. \& Tress, W. Application of stratum-specific likelihood ratios in mental health screening. Soc. Psychiatry Psychiatr. Epidemiol. 35, 375-379 (2000).

49. Sakurai, K., Nishi, A., Kondo, K., Yanagida, K. \& Kawakami, N. Screening performance of K6/K10 and other screening instruments for mood and anxiety disorders in Japan. Psychiatry Clin. Neurosci. 65, 434-441. https://doi.org/10.1111/j.1440-1819.2011.02236 .X (2011).

50. Yamaoka, Y. et al. The relationship between raising a child with a disability and the mental health of mothers compared to raising a child without disability in japan. SSM Popul. Health 2, 542-548. https://doi.org/10.1016/j.ssmph.2016.08.001 (2016).

\section{Acknowledgements}

This study was supported by the Japanese Society for the Promotion of Science KAKENHI (grant number: 16K16631 and 17K12338), a grant from the National Center for Child Health and Development (grant number: 2019B-3), and MHLW DA Program (grant number: 20DA1002). The sponsors of this study played no role in the research design, data analysis, or interpretation of the data. We would like to thank Ai Aoki at the University of Tokyo for her comments and advice regarding the manuscript. We would like to thank Editage (https://www. editage.jp) for English language editing.

\section{Author contributions}

K.T., M.S., and T.K. designed the study. K.T. carried out the statistical analysis and drafted the initial manuscript, and M.S. and T.K. critically revised it for important intellectual content. All the authors approved the final manuscript as submitted and agree to be accountable for all aspects of the work.

\section{Competing interests}

The authors declare no competing interests.

\section{Additional information}

Supplementary information is available for this paper at https://doi.org/10.1038/s41598-020-70727-2.

Correspondence and requests for materials should be addressed to K.T.

Reprints and permissions information is available at www.nature.com/reprints.

Publisher's note Springer Nature remains neutral with regard to jurisdictional claims in published maps and institutional affiliations.

Open Access This article is licensed under a Creative Commons Attribution 4.0 International

License, which permits use, sharing, adaptation, distribution and reproduction in any medium or format, as long as you give appropriate credit to the original author(s) and the source, provide a link to the Creative Commons licence, and indicate if changes were made. The images or other third party material in this article are included in the article's Creative Commons licence, unless indicated otherwise in a credit line to the material. If material is not included in the article's Creative Commons licence and your intended use is not permitted by statutory regulation or exceeds the permitted use, you will need to obtain permission directly from the copyright holder. To view a copy of this licence, visit http://creativecommons.org/licenses/by/4.0/.

(C) The Author(s) 2020 